University of Nebraska - Lincoln

DigitalCommons@University of Nebraska - Lincoln

2006

\title{
Colorectal Cancer in U.S. Adults Younger than 50 Years of Age, 1998-2001
}

Temeika L. Fairley

Centers for Disease Control and Prevention, tfairley@cdc.gov

Cheryll J. Cardinez

Centers for Disease Control and Prevention

Jim Martin

Virginia Department of Health, jim.martin@vdh.virginia.gov

Linda Alley

Centers for Disease Control and Prevention

Carol Friedman

Centers for Disease Control and Prevention, cxf7@cdc.gov

See next page for additional authors

Follow this and additional works at: https://digitalcommons.unl.edu/publichealthresources

Part of the Public Health Commons

Fairley, Temeika L.; Cardinez, Cheryll J.; Martin, Jim; Alley, Linda; Friedman, Carol; Edwards, Brenda K.; and Jamison, Patricia, "Colorectal Cancer in U.S. Adults Younger than 50 Years of Age, 1998--2001" (2006).

Public Health Resources. 249.

https://digitalcommons.unl.edu/publichealthresources/249

This Article is brought to you for free and open access by the Public Health Resources at DigitalCommons@University of Nebraska - Lincoln. It has been accepted for inclusion in Public Health Resources by an authorized administrator of DigitalCommons@University of Nebraska - Lincoln. 


\section{Authors}

Temeika L. Fairley, Cheryll J. Cardinez, Jim Martin, Linda Alley, Carol Friedman, Brenda K. Edwards, and Patricia Jamison 


\section{Descriptive Epidemiology of Colorectal Cancer in the United States, 1998-2001, Utilizing Data from the NPCR and SEER Programs}

Supplement to Cancer

\section{Colorectal Cancer in U.S. Adults Younger than 50 Years of Age, 1998-2001}

\author{
Temeika L. Fairley, PhD ${ }^{1}$ \\ Cheryll J. Cardinez, MSPH ${ }^{1}$ \\ Jim Martin, $\mathrm{PhD}^{2}$ \\ Linda Alley, PhD, RN ${ }^{1}$ \\ Carol Friedman, ${ }^{1}{ }^{1}$ \\ Brenda Edwards, PhD $^{3}$ \\ Patricia Jamison, $\mathrm{MPH}^{1}$
}

\begin{abstract}
${ }^{1}$ Division of Cancer Prevention and Control, National Center for Chronic Disease Prevention and Control, Centers for Disease Control and Prevention, Atlanta, Georgia.

${ }^{2}$ Virginia Cancer Registry, Virginia Department of Health, Richmond, Virginia.

${ }^{3}$ Cancer Surveillance Research Program, Division of Cancer Control and Population Sciences, National Cancer Institute, Bethesda, Maryland.
\end{abstract}

Supported by the Centers for Disease Control and Prevention's NPCR.

We appreciate the in-kind support from all the contributors to this monograph and also are grateful for the contributions of Jessica King for the preparation of analytic files and to Faruque Ahmed for his leadership of the CRC monograph project.

The findings and conclusions in this report are those of the authors and do not necessarily represent the views of the Centers for Disease Control and Prevention.

Address for reprints: Temeika L. Fairley, PhD, Centers for Disease Control and Prevention, Division of Cancer Prevention and Control, Comprehensive Cancer Control Branch, 4770 Buford Hwy, NE K-57, Atlanta, GA 30341, USA; Fax: 770-4884759; E-mail: tfairley@cdc.gov

Received March 2, 2006; accepted March 21, 2006.
BACKGROUND. Colorectal cancer (CRC) incidence rates are increasing among persons younger than 50 years of age, a population routinely not screened unless an individual has a high risk of CRC. This population-based study focuses primarily on describing the CRC burden for persons in this age group.

METHODS. The data used for this study were derived from the National Program of Cancer Registries (NPCR) and Surveillance, Epidemiology, and End Results (SEER) surveillance systems. Age-adjusted incidence rates, rate ratios, and their corresponding 95\% confidence intervals were calculated.

RESULTS. CRC is ranked among the top 10 cancers occurring in males and females aged 20-49 years regardless of race. Persons younger than 50 years were more likely to present with less localized and more distant disease than do older adults. Among younger adults, age-adjusted incidence rates for poorly differentiated cancers were twice as high as rates for well-differentiated cancers. Incidence rates for poorly differentiated cancers were $60 \%$ higher than that for welldifferentiated cancers diagnosed in older adults. Rates were significantly higher for blacks and significantly lower for Asians/Pacific Islanders when compared with that for whites for the most demographic and tumor characteristics examined.

CONCLUSIONS. This study confirms the findings of previous population-based studies suggesting that younger patients present with more advanced disease than do older patients. This study also identifies racial and ethnic disparities in CRC incidence in this population. These findings suggest the need for additional studies to understand the behavior and etiology of CRC in blacks. Cancer 2006;107(5 Suppl):1153-61. (C) 2006 American Cancer Society.

KEYWORDS: young adults, colorectal, cancer, incidence, colon, rectal, screening.

n 2002, there were 139,534 new cases of colorectal cancer (CRC) diagnosed in the United States, based on $93 \%$ of the U.S. population. ${ }^{1}$ Of these cases, $127,743(91.5 \%)$ occurred in persons older than 50 years of age, and 11,791 (8.5\%) occurred in persons younger than 50 years (P. Wingo, January 13, 2006, personal communication). A reported $2 \%$ to $9 \%$ of all CRC cases diagnosed are in persons younger than 50 years. ${ }^{2,3}$ Previous research has shown increasing CRC incidence rates among persons younger than 50 years, ${ }^{4-6}$ a population not routinely screened unless individuals have a high risk of CRC (i.e., those with family history or other predisposing conditions). ${ }^{7-9}$

Several clinic- and hospital-based investigations among persons younger than 50 years have reported that those in this age group 
present with more advanced stages of disease than do older adults, but discrepancies exist concerning the prognosis for survival among younger patients. ${ }^{2,5,10,11}$ Population-based descriptive studies suggest that persons younger than 50 years present with more advanced disease and have fewer localized tumors than do older adults ${ }^{6,10,12,13}$ and that the incidence rates and the percentage of proximal or rightsided cancers are higher for blacks than for whites. ${ }^{14,15}$ Recent population-based studies have also documented that survival was not significantly worse for persons younger than 50 years than for older adults. ${ }^{2}$

Previous studies of CRC in individuals younger than 50 years had relatively small sample sizes and focused primarily on persons younger than 40 years. Advances in cancer surveillance, such as expansions in geographic coverage, allow description of CRC incidence in this population. This population-based study focuses on describing the CRC burden for persons younger than 50 years by sociodemographics and tumor characteristics such as stage, tumor grade, and anatomic subsite. Inclusion of cases among individuals aged 40-49 years allows us to describe the CRC burden for individuals nearest the recommended CRC screening age. Although the main emphasis of this study is CRC in persons younger than 50 years of age, we have included some data for older adults for comparison.

\section{METHODS}

Data

The 1998-2001 combined National Program of Cancer Registries (NPCR) and Surveillance, Epidemiology, and End Results (SEER) data used for this analysis have been described elsewhere. ${ }^{16}$ Briefly, 39 statewide registries and the metropolitan Atlanta and District of Columbia central cancer registries were included in the data set, which covers $88 \%$ of the U.S. population. The entire dataset comprised a total of 542,149 patients with invasive colorectal cancer (CRC), of whom 42,017 were younger than 50 years.

\section{Description of Variables}

The sociodemographic variables included the following: age (0-19 years, $20-39$ years, $40-49$ years, $\geq 50$ years), sex, race (white, black, Asians/Pacific Islanders [API], and other races combined [American Indians/Alaska Natives, other, and unknown]), ethnicity (Hispanic, non-Hispanic), and U.S. Census region (Northeast, Midwest, South, and West). For race,
American Indians/Alaska Natives were combined with other and unknown because of the small overall percentages. The tumor characteristics included the following: anatomical subsite (proximal colon [C18.0C18.5], distal colon [C18.6-C18.7], colon, NOS [C18.8C18.9, C26.0], and rectum $[\mathrm{C} 19.9, \mathrm{C} 20.9])^{17}$; SEER summary stage (localized, regional, distant, and unstaged) ${ }^{18}$; and grade at diagnosis (well differentiated, moderately differentiated, poorly differentiated, undifferentiated, and unknown). SEER summary stage data were submitted for only 3 regions in California (San Francisco-Oakland, San Jose-Monterrey, and Los Angeles). Thus, analyses using the SEER summary stage variable include 39,560 patients younger than 50 years and 472,294 patients aged 50 years or older. Analyses for grade were limited to microscopically confirmed cases only and include 41,467 patients younger than 50 years and 481,163 patients aged 50 years or older.

\section{Analysis}

All analyses were conducted in SEER*Stat version 6.1.4. ${ }^{19}$ Rates were age-adjusted to the 2000 U.S. standard population by 5-year age groups; corresponding 95\% confidence intervals were based on the gamma method..$^{20}$ Rate ratios and corresponding 95\% confidence intervals were calculated and used for rate comparisons. A significance level of $P=0.05$ was used for these analyses. The top 10 cancers by race, sex, and 3 age groups (0-19, 20-39, and 40-49 years) were ranked on the basis of 27 cancer sites to assess the burden of CRC relative to other cancers common in this age group.

\section{RESULTS}

Our results indicate that CRC ranked among the top 4 cancers occurring in males and females aged 40-49 years, regardless of race (Fig. 1), and it was the most frequently diagnosed cancer among 40 to 49 -year-old API males (data not shown). Among 20 to 39-yearolds, CRC ranked among the top 10 cancers (Fig. 1) and was the second most frequently diagnosed cancer among black and API males (data not shown). CRC was not ranked among the top 10 cancers diagnosed in males and females aged 0-19 years (data not shown).

A majority (74.3\%) of cases was diagnosed in adults aged $40-49$ years; $25.1 \%$ were diagnosed in persons aged $20-39$ years; $0.5 \%$ were diagnosed in those younger than 20 years of age. The percentages of persons younger than 50 years and of persons aged 50 or older were similar for males and females 

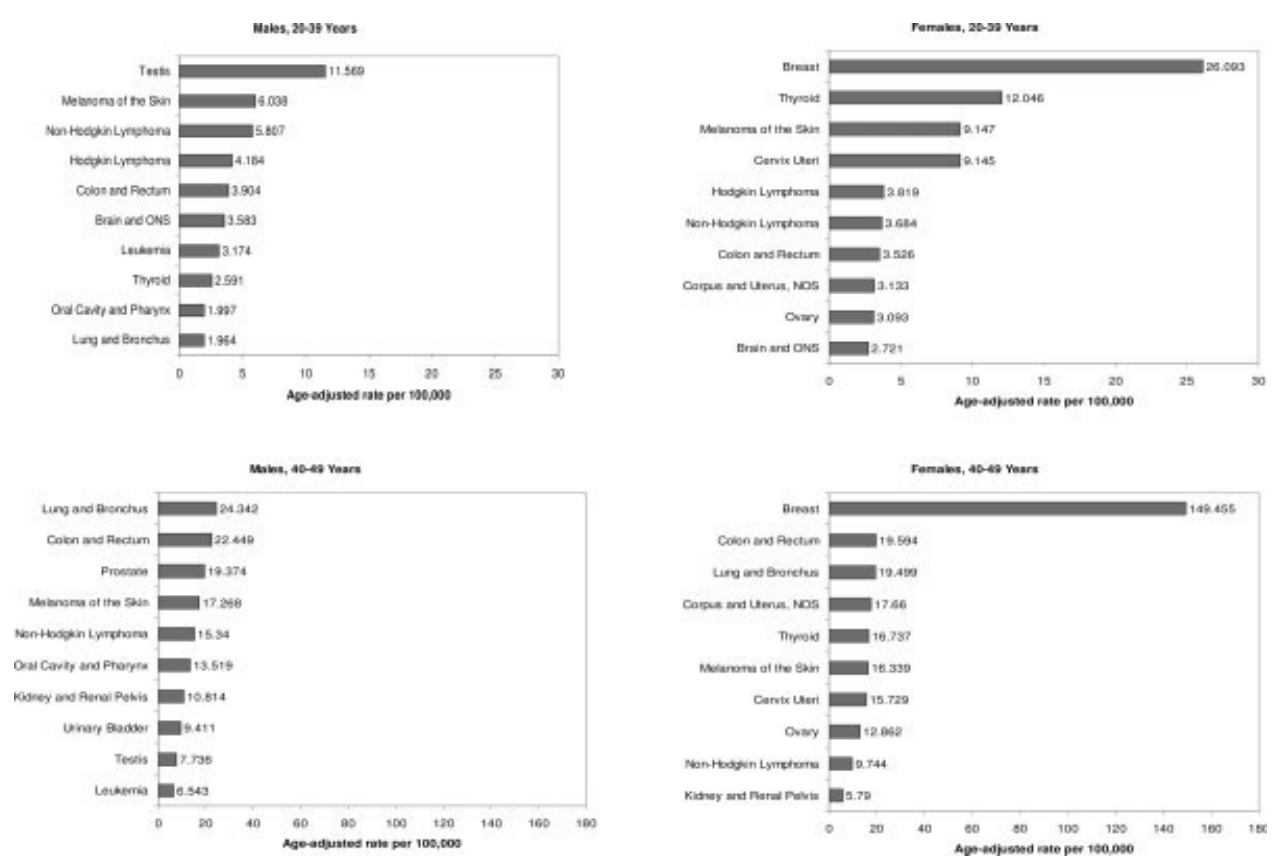

FIGURE 1. Top 10 invasive cancer sites by age and sex, adults 20-49 years of age, United States, 1998-2001. Rates are per 100,000 and age adjusted to the 2000 U.S. population standard. Data are from cancer registries that participate in the NPCR and/or the SEER Program: Alabama, Alaska, Arizona, Atlanta, California, Colorado, Connecticut, District of Columbia, Florida, Hawaii, Idaho, Illinois, Indiana, lowa, Kansas, Kentucky, Louisiana, Maine, Massachusetts, Michigan, Minnesota, Missouri, Montana, Nebraska, New Jersey, New Mexico, New York, North Carolina, Ohio, Oklahoma, Oregon, Pennsylvania, Rhode Island, South Carolina, Texas, Utah, Vermont, Washington, West Virginia, Wisconsin, Wyoming. These registries had high-quality data for the period 1998-2001 and collectively cover $88 \%$ of the U.S. population.

(Table 1). Persons younger than 50 years were more likely than older adults to be black (14.3\%), API (3.9\%), and Hispanic (9.4\%). There were more rectal cancers diagnosed among persons younger than 50 years of age than among older adults ( $37 \%$ vs. $26.2 \%$ ). However, proximal colon cancers were diagnosed less frequently in persons younger than 50 years than among older adults (32.1\% vs. $42.6 \%)$. Ageadjusted incidence rates were highest for rectal cancers diagnosed in persons younger than 50 years and for proximal cancers diagnosed in persons older than 50. Compared with older adults, persons younger than 50 years presented with less localized $(29.7 \%$ vs. $35.1 \%)$ and more distant (21.9\% vs. $16.0 \%)$ disease. The younger group also had fewer well-differentiated $(8.8 \%$ vs. $10.0 \%)$ and more poorly differentiated (18.4\% vs. $16.3 \%)$ tumors. In younger adults, ageadjusted incidence rates for poorly differentiated cancers were twice as high as rates for well-differentiated cancers; in older adults, incidence rates for poorly differentiated cancers were $60 \%$ higher than that for well-differentiated cancers. Rates differed by U.S. Census region between the 2 age groups. The average annual age-adjusted incidence rate among younger persons was highest for cases diagnosed in the South, followed by the Northeast, Midwest, and West. Among older persons, the highest rates were reported for the Northeast followed by the Midwest, South, and West.

Age-adjusted incidence rates were significantly higher for blacks and significantly lower for API than for whites for most demographic and tumor characteristics examined (Table 2). Rates for all racial populations were similar among persons aged 0-19 and 20-39 years, but among adults aged 40-49 years, rates for blacks were almost $40 \%$ higher than that for whites and almost $60 \%$ higher than that for API. These differences were observed primarily in adults aged 4549 years for both males and females (Fig. 2). Blacks $(38.2 \%)$ had more proximal cancers than did whites $(31.4 \%)$ or APIs (26.1\%; Fig. 3). The rate of proximal colon cancer in blacks was $61 \%$ higher than that in whites and $200 \%$ higher than that in APIs. API had more rectal cancers $(42.7 \%)$ than did whites $(38.0 \%)$ or blacks $(29.6 \%)$, but the rates of rectal cancer did not differ appreciably by race. The rates for proximal colon and rectal cancers were significantly higher than that for distal colon cancers for all racial groups (Table 2). Examination of stage by race among persons younger than 50 years revealed that blacks presented with more distant and unstaged disease and less localized disease than did whites and APIs (Fig. 4). 
TABLE 1

Demographic and Tumor Characteristics for Invasive Colon and Rectum Cancers by Age Group, United States, 1998-2001*

\begin{tabular}{|c|c|c|c|c|c|c|c|c|}
\hline & \multicolumn{4}{|c|}{ 0-49 Years } & \multicolumn{4}{|c|}{$>50$ Years } \\
\hline & $N$ & $\%$ & $\begin{array}{l}\text { Age-adjusted } \\
\operatorname{rate}^{\dagger}(95 \% \mathrm{CI})\end{array}$ & $\begin{array}{l}\text { Rate ratio } \\
(95 \% \mathrm{CI})\end{array}$ & $N$ & $\%$ & $\begin{array}{l}\text { Age-adjusted rate } \\
(95 \% \text { CI })\end{array}$ & $\begin{array}{l}\text { Rate ratio } \\
(95 \% \text { CI })\end{array}$ \\
\hline Total & 42,017 & & $6.0(5.9-6.0)$ & & 500,132 & & $185.6(185.1-186.1)$ & \\
\hline \multicolumn{9}{|l|}{ Age (yrs) } \\
\hline $0-19$ & 225 & 0.5 & $0.1(0.1-0.1)$ & & & & & \\
\hline $20-39$ & 10,554 & 25.1 & 3.7 (3.6-3.8) & & & & & \\
\hline $40-49$ & 31,238 & 74.3 & $21.0(20.8-21.2)$ & & & & & \\
\hline \multicolumn{9}{|l|}{ Sex } \\
\hline Male & 22,164 & 52.8 & $6.3(6.2-6.4)$ & $1.1(1.1-1.2)$ & 251,031 & 50.2 & $222.6(221.7-223.5)$ & $1.4(1.4-1.4)$ \\
\hline Female & 19,853 & 47.2 & $5.6(5.5-5.7)$ & Referent & 249,101 & 49.8 & $158.3(157.7-158.9)$ & Referent \\
\hline \multicolumn{9}{|l|}{ Race } \\
\hline White & 33,464 & 79.6 & $5.7(5.6-5.8)$ & Referent & 441,395 & 88.3 & $184.3(183.7-184.8)$ & Referent \\
\hline Black & 6024 & 14.3 & $7.6(7.4-7.8)$ & $1.3(1.3-1.4)$ & 42,290 & 8.5 & $198.1(196.2-200.1)$ & $1.1(1.1-1.1)$ \\
\hline Asian/Pacific Islander & 1618 & 3.9 & $5.0(4.8-5.3)$ & $0.9(0.8-0.9)$ & 10,156 & 2.0 & $134.7(132.0-137.5)$ & $0.7(0.7-0.7)$ \\
\hline Other (AI/AN, other, unknown) & 911 & 2.2 & $\ddagger$ & 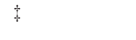 & 6291 & 1.3 & $\ddagger$ & $\ddagger$ \\
\hline \multicolumn{9}{|l|}{ Ethnicity ${ }^{\S}$} \\
\hline Non-Hispanic & 38,078 & 90.6 & $6.1(6.0-6.2)$ & Referent & 477,212 & 95.4 & $188.0(187.5-188.6)$ & Referent \\
\hline Hispanic & 3937 & 9.4 & $4.9(4.7-5.0)$ & $0.8(0.8-0.8)$ & 22,892 & 4.6 & $145.8(143.9-147.8)$ & $0.8(0.8-0.8)$ \\
\hline \multicolumn{9}{|l|}{ U.S. Census Region } \\
\hline Northeast & 9376 & 22.3 & $6.2(6.0-6.3)$ & Referent & 129,788 & 26.0 & $207.4(206.3-208.5)$ & Referent \\
\hline Midwest & 10,671 & 25.4 & $5.9(5.8-6.0)$ & $1.0(0.9-1.0)$ & 136,318 & 27.3 & $193.8(192.8-194.8)$ & $0.9(0.9-0.9)$ \\
\hline South & 13,224 & 31.5 & $6.7(6.6-6.8)$ & $1.1(1.1-1.1)$ & 136,644 & 27.3 & $176.6(175.6-177.5)$ & $0.9(0.8-0.9)$ \\
\hline West & 8746 & 20.8 & $5.0(4.9-5.1)$ & $0.8(0.8-0.8)$ & 97,382 & 19.5 & $164.7(163.6-165.7)$ & $0.8(0.8-0.8)$ \\
\hline \multicolumn{9}{|l|}{ Tumor Location } \\
\hline Proximal colon (C18.0-C18.5) & 13,486 & 32.1 & $1.9(1.9-1.9)$ & $1.2(1.2-1.3)$ & 212,893 & 42.6 & $79.0(78.6-79.3)$ & $1.7(1.7-1.7)$ \\
\hline Distal colon (C18.6-C18.7) & 10,986 & 26.1 & $1.6(1.5-1.6)$ & Referent & 125,108 & 25.0 & $46.4(46.2-46.7)$ & Referent \\
\hline Colon, NOS (C18.8-C18.9, C26.0) & 2005 & 4.8 & $0.3(0.3-0.3)$ & $0.2(0.2-0.2)$ & 31,001 & 6.2 & $11.5(11.4-11.6)$ & $0.2(0.2-0.3)$ \\
\hline Rectum $(\mathrm{C} 19.9, \mathrm{C} 20.9)$ & 15,540 & 37.0 & $2.2(2.2-2.2)$ & $1.4(1.4-1.4)$ & 131,130 & 26.2 & $48.7(48.4-49.0)$ & $1.0(1.0-1.1)$ \\
\hline \multicolumn{9}{|l|}{ SEER Summary Stagel } \\
\hline Localized & 11,757 & 29.7 & $1.8(1.8-1.8)$ & Referent & 165,803 & 35.1 & $65.7(65.4-66.0)$ & Referent \\
\hline Regional & 16,016 & 40.5 & $2.4(2.4-2.5)$ & $1.4(1.3-1.4)$ & 183,092 & 38.8 & $72.6(72.2-72.9)$ & $1.1(1.1-1.1)$ \\
\hline Distant & 8644 & 21.9 & $1.3(1.3-1.3)$ & $0.7(0.7-0.8)$ & 75,369 & 16.0 & $29.9(29.7-30.1)$ & $0.5(0.5-0.5)$ \\
\hline Unstaged & 3143 & 7.9 & $0.5(0.5-0.5)$ & $0.3(0.3-0.3)$ & 48,030 & 10.2 & $19.0(18.9-19.2)$ & $0.3(0.3-0.3)$ \\
\hline \multicolumn{9}{|l|}{ Grade } \\
\hline Well differentiated; Grade I & 3634 & 8.8 & $0.5(0.5-0.5)$ & Referent & 48,252 & 10.0 & $17.9(17.7-18.1)$ & Referent \\
\hline Moderately differentiated; Grade II & 22,699 & 54.7 & $3.2(3.2-3.3)$ & $6.3(6.0-6.5)$ & 291,248 & 60.5 & $108.1(107.7-108.5)$ & $6.0(6.0-6.1)$ \\
\hline Poorly differentiated; Grade III & 7649 & 18.4 & $1.1(1.1-1.1)$ & $2.1(2.0-2.2)$ & 78,264 & 16.3 & $29.0(28.8-29.2)$ & $1.6(1.6-1.6)$ \\
\hline Undifferentiated; Grade IV & 394 & 1.0 & $0.1(0.1-0.1)$ & $0.1(0.1-0.1)$ & 3304 & 0.7 & $1.2(1.2-1.3)$ & $0.1(0.1-0.1)$ \\
\hline Unknown & 7091 & 17.1 & $1.0(1.0-1.0)$ & $1.9(1.9-2.0)$ & 60,095 & 12.5 & $22.3(22.1-22.5)$ & $1.2(1.2-1.3)$ \\
\hline
\end{tabular}

* Data are from population-based cancer registries that participate in the National Program of Cancer Registries (NPCR) and/or the Surveillance Epidemiology and End Results (SEER) Program and meet highquality data criteria: Alabama, Alaska, Arizona, California, Colorado, Connecticut, District of Columbia, Florida, Metro Atlanta (Georgia), Hawaii, Idaho, Illinois, Indiana, Iowa, Kansas, Kentucky, Louisiana, Maine, Massachusetts, Michigan, Minnesota, Missouri, Montana, Nebraska, New Jersey, New Mexico, New York, North Carolina, Ohio, Oklahoma, Oregon, Pennsylvania, Rhode Island, South Carolina, Texas, Utah, Vermont, Washington, West Virginia, Wisconsin, Wyoming. These registries cover approximately 88\% of the U.S. population.

${ }^{\dagger}$ Rates are per 100,000 and age-adjusted to the 2000 U.S. population standard.

* Rates were not calculated because population denominator was not available.

${ }^{\S}$ Ethnicity is reported using the NAACCR Hispanic Identification Algorithm for NPCR registries and Hispanic/Spanish Origin (NAACCR no. 190) for SEER registries. Unknown ethnicity was not included since there were fewer than 50 in the entire dataset.

I Some regions in California did not contribute SEER summary stage data. The sample sizes are 39,560 for 0-49 years and 472,294 for >50 years.

- Grade analyses were limited to microscopically confirmed cases. The sample sizes are 41,467 for 0-49 years and 481,163 for $>50$ years.

\section{DISCUSSION}

To our knowledge, this is the largest populationbased study of CRC among persons younger than 50 years of age and is the first to describe the burden of CRC in 40 to 49 -year-olds. This large nationwide study revealed that CRC is one of the 10 most commonly diagnosed cancers among men and women aged 20-49 years. Such findings have not been previously reported for the United States. However, a recent study that assessed the burden of cancer in 


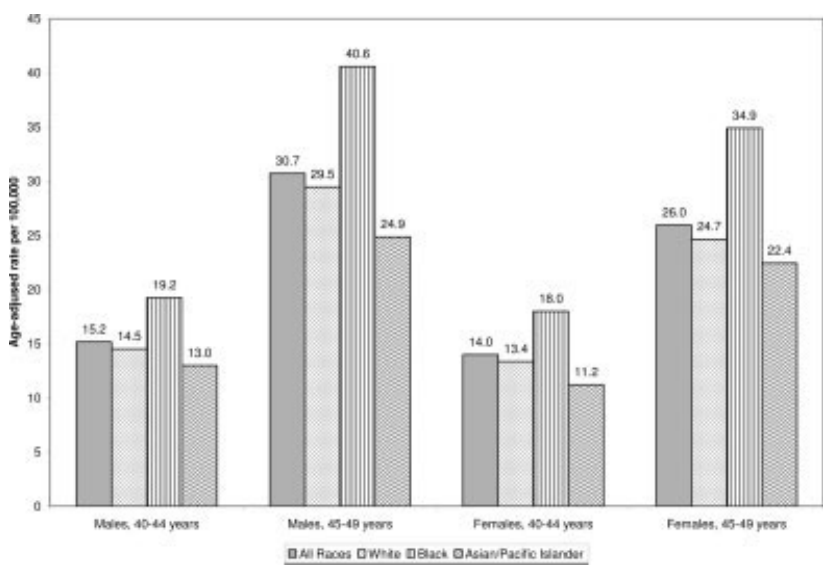

FIGURE 2. Invasive colon and rectum cancer rates by race and sex, adults 40-49 years of age, United States, 1998-2001. Rates are per 100,000 and age adjusted to the 2000 U.S. population standard. Data are from population-based cancer registries that participate in the NPCR and/or the SEER Program and meet high-quality data criteria: Alabama, Alaska, Arizona, California, Colorado, Connecticut, District of Columbia, Florida, Metro Atlanta (Georgia), Hawaii, Idaho, Illinois, Indiana, lowa, Kansas, Kentucky, Louisiana, Maine, Massachusetts, Michigan, Minnesota, Missouri, Montana, Nebraska, New Jersey, New Mexico, New York, North Carolina, Ohio, Oklahoma, Oregon, Pennsylvania, Rhode Island, South Carolina, Texas, Utah, Vermont, Washington, West Virginia, Wisconsin, Wyoming. These registries cover approximately $88 \%$ of the U.S. population.

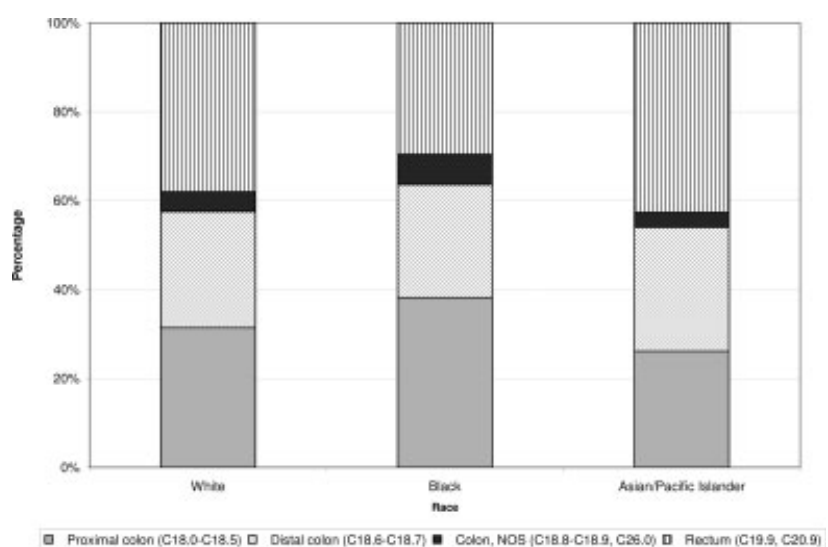

FIGURE 3. Percentage distribution of tumor location for invasive colon and rectum cancers by race, persons from birth to 49 years of age, United States, 1998-2001. Data are from population-based cancer registries that participate in the NPCR and/or the SEER Program and meet high-quality data criteria: Alabama, Alaska, Arizona, California, Colorado, Connecticut, District of Columbia, Florida, Metro Atlanta (Georgia), Hawaii, Idaho, Illinois, Indiana, lowa, Kansas, Kentucky, Louisiana, Maine, Massachusetts, Michigan, Minnesota, Missouri, Montana, Nebraska, New Jersey, New Mexico, New York, North Carolina, Ohio, Oklahoma, Oregon, Pennsylvania, Rhode Island, South Carolina, Texas, Utah, Vermont, Washington, West Virginia, Wisconsin, Wyoming. These registries cover approximately $88 \%$ of the U.S. population. NOS.

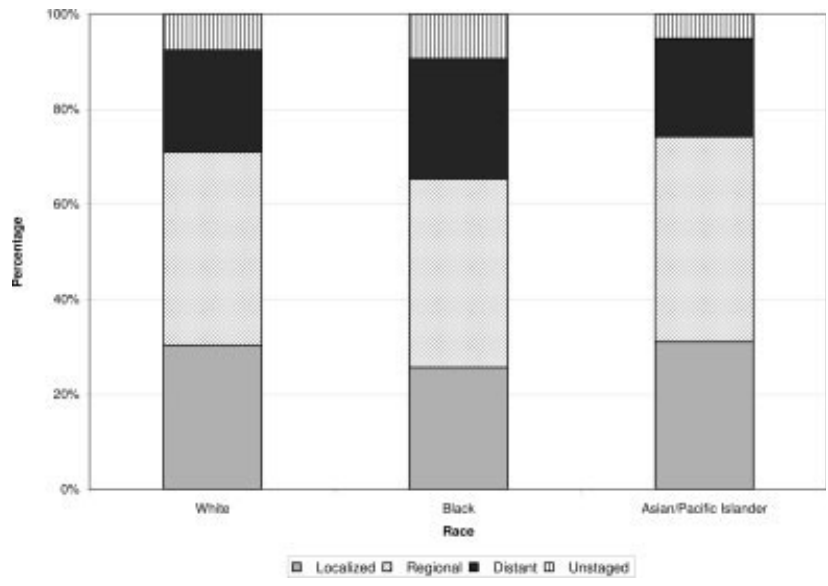

FIGURE 4. Percentage distribution of SEER Summary Stage for invasive colon and rectum cancers by race, persons from birth to 49 years of age, United States, 1998-2001. Data are from population-based cancer registries that participate in the NPCR and/or the SEER Program and meet high-quality data criteria: Alabama, Alaska, Arizona, California, Colorado, Connecticut, District of Columbia, Florida, Metro Atlanta (Georgia), Hawaii, Idaho, Illinois, Indiana, lowa, Kansas, Kentucky, Louisiana, Maine, Massachusetts, Michigan, Minnesota, Missouri, Montana, Nebraska, New Jersey, New Mexico, New York, North Carolina, Ohio, Oklahoma, Oregon, Pennsylvania, Rhode Island, South Carolina, Texas, Utah, Vermont, Washington, West Virginia, Wisconsin, Wyoming. These registries cover approximately $88 \%$ of the U.S. population.

Overall, the age-adjusted incidence rates reported in our study are similar to those of previous population-based studies. All races combined, increasing age-adjusted incidence rates with increasing age and higher rates for males than for females were documented, findings consistent with numerous published reports. ${ }^{10,13,15,24-26}$ We also found that younger people present with later stage disease and poorer tumor grades at diagnosis. ${ }^{27}$ No definitive explanations for these differences have been determined. It is possible, however, that younger patients present with later disease because they are not screened $^{6}$ or are at increased risk because of a higher prevalence of conditions predisposing them to CRC. To determine the impact of these explanations on stage of disease and tumor grade at diagnosis, we need to collect specific information on risk factors for developing CRC, such as having a family history of CRC, colorectal polyps, chronic inflammatory bowel disease, and history of genetic abnormalities such as familial adenomatous polyposis (FAP) or hereditary nonpolyposis colorectal cancer (HNPCC). Previous studies have documented that approximately $8 \%$ of young colorectal patients have $\mathrm{FAP}^{12}$ and approximately $10 \%$ of cases occur in families with HNPCC. ${ }^{28}$ In this study, almost $75 \%$ of the persons with CRC 
younger than 50 years were $40-49$ years old. Many of these individuals may have had an increased risk for developing CRC because conditions like HNPCC usually appear in this age group. ${ }^{29}$

Studies geared toward persons younger than 50 years of age may be essential to understanding the potential etiologic differences in this age group. For example, population-based case-control studies, such as the Women's CARE study, ${ }^{30}$ could be designed to examine risk factors for CRC in a young population. The National Cancer Institute established the Cancer Family Registries (CFR) to facilitate both populationbased and clinic-based interdisciplinary studies in the genetic epidemiology of cancer and to provide a flexible, comprehensive, and collaborative research infrastructure. Several CFR programs systematically collect family history information, epidemiologic and clinical data, and related biological specimens from individuals with CRC and their families. ${ }^{31}$

Differences in stage and grade of disease among younger cases may also be attributable to delays in diagnosis caused in part by delays in patient presentation, lack of access to medical care, or misdiagnosis by the physician. Studies have reported delays in presentation as long as 9 years, mostly due to patient factors such as lack of knowledge about CRC symptoms, particularly among persons younger than 50 years. $^{2,11,32,33}$ Other studies have identified delays due to physician misdiagnosis. ${ }^{34,35}$ Both instances emphasize the need for increased awareness about the incidence of CRC in persons younger than 50 years. Additional patient and provider education on the CRC symptoms and signs, given to patients before the recommended screening age of 50 years, may decrease the delays in diagnosis and subsequently positively affect the stage of disease at diagnosis.

Current efforts in CRC prevention focus primarily on screening and the removal of any precancerous polyps or abnormal growths detected in individuals aged 50 years and older. Because persons younger than 50 years are less likely to be screened for CRC than are older adults, some attention should be given to preventing disease in young adults by addressing modifiable risk factors such as smoking, alcohol consumption, physical inactivity, excess body weight, and poor diet. ${ }^{36}$ Studies have shown that increased physical activity and maintaining a healthy weight can decrease the risk for CRC. ${ }^{37}$ However, excess body weight and physical inactivity account for only approximately one fourth to one third of cancers of the colon. ${ }^{38}$ Further study is needed to understand fully the effect of these and other risk factors on persons younger than 50 years.
Our investigation of the differences in the occurrence of cancer by geographic area among persons younger than 50 years and among older adults revealed that race may have influenced our results. In the younger age group, incidence rates were higher for blacks than that for any other population. When we examined the incidence rates within Census regions by race for this age group, the rates for blacks were higher than that for whites in all regions, with the highest rates for blacks being in the South. Thus, among those younger than 50 years, the incidence rates for blacks affect the pattern of incidence rates by Census region described in this study. This pattern, however, is not consistent with that of the older population. The pattern of incidence rates by Census region appears to follow the rates for whites in each region, which were highest in the Northeast, followed by the Midwest, South, and West.

Previous studies reported that blacks present with CRC at a younger age than do whites ${ }^{13}$ and with more late-stage cancers than do whites and API. ${ }^{10,13,15}$ Our results are consistent with those findings. We also found that blacks have higher rates of proximal cancers than do whites ${ }^{10}$ or API. ${ }^{25}$ Recent recommendations were made to lower the CRC screening age for blacks from 50-45 years and to require the use of colonoscopy as the first-line screening procedure for blacks. ${ }^{39}$ CRC screening using flexible sigmoidoscopies and colonoscopies has been consistently associated with lower CRC incidence and mortality. ${ }^{40}$ Colonoscopy is the most sensitive and specific test for detecting cancer and large polyps; however, there are higher risks associated with this test than with other screening tests for CRC. ${ }^{41}$ It is not certain whether the potential added benefits of colonoscopy relative to screening alternatives are large enough to justify the added risks and inconvenience to all patients. ${ }^{41}$ More research is needed to determine whether current screening recommendations need to be modified for blacks and what might be the impact of such modifications on mortality and survival in this population. Current population-based studies should be considered by the U.S. Preventive Task Force and the American Cancer Society when considering the re-examination of the recommended screening age of 50 years for those at average risk, especially for blacks.

We note several potential limitations of this study. Although cancer incidence data used in this study were from population-based cancer registries in the United States that use standard codes for race, the collection of race information has not been standardized. Thus, some misclassification is expected regarding race, particularly for API and Hispanics. 
Second, population coverage for the South is about $70 \%$, and so, rates provided for this region may not be generalizable to the entire South. It will be important to re-examine these estimates as population coverage for this region increases. Third, we documented a substantial number of tumors that were unstaged or had an unknown grade. The impact of these findings on our study is not clear because the percentages for unknown stage and grade are higher among blacks than among whites and APIs. Finally, because of changes in staging systems/protocols for all registries, our analysis included data staged using both SEER Summary Stage 1977 for 1998-2000 data and SEER Summary Stage 2000 for 2001 data. The extent of the effect of these changes on our results is likely negligible for CRC. ${ }^{42}$

In summary, we have used population-based data to describe the nationwide burden of CRC among persons younger than 50 years of age in the United States. Our study demonstrates that CRC is one of the most frequently diagnosed cancers in young adults, particularly in 40 to 49 -year-olds. This important finding has not been previously reported in the United States. We also confirmed the findings of previous population-based studies suggesting that younger patients present with more aggressive disease in terms of stage and grade at presentation than do older patients. This population may be diagnosed at later stages and have a worse disease prognosis; therefore, emphasis should also be placed on provider and patient education about disease symptoms as well as further investigation of risk factors for developing CRC in this age group. Also consistent with earlier studies, our study identified racial and ethnic disparities in CRC incidence and stage at diagnosis in this population. Higher proportions of proximal cancers among blacks than in other racial populations, coupled with more late-stage disease in this population, suggest the need for additional studies to understand the behavior and etiology of this disease in blacks. Such studies may be necessary to support or refute current recommendations to modify the CRC screening guidelines in blacks. ${ }^{39}$

\section{REFERENCES}

1. United States Cancer Statistics Working Group. United States Cancer Statistics: 2002 Incidence and Mortality. Atlanta, GA: Department of Health and Human Services, Centers for Disease Control and Prevention and National Cancer Institute; 2005.

2. O'Connell JB, Maggard MA, Liu JH, Etzioni DA, Livingston $\mathrm{EH}$, Ko CY. Do young colon cancer patients have worse outcomes? World J Surg. 2004;28:558-562.
3. Parkin DM, Whelan S, Ferlay J, Raymond L, Young J.Cancer Incidence in Five Continents. Vol 7. Lyon, France: International Agency for Research on Cancer; 1997.

4. Heys SD, O'Hanrahan TJ, Brittenden J, Eremin O. Colorectal cancer in young patients: A review of the literature. Eur J Surg Oncol. 1994;20:225-231.

5. Minardi AJ Jr, Sittig KM, Zibari GB, McDonald JC. Colorectal cancer in the young patient. Am Surg. 1998;64:849-853.

6. O'Connell JB, Maggard MA, Liu JH, Etzioni DA, Livingston $\mathrm{EH}, \mathrm{Ko} \mathrm{CY}$. Rates of colon and rectal cancers are increasing in young adults. Am Surg. 2003;69:866-872.

7. American Cancer Society. Colorectal Cancer Facts and Figures Special Edition 2005. Atlanta, GA: American Cancer Society; 2005.

8. Pignone $\mathrm{M}$, Rich $\mathrm{M}$, Teutsch SM, Berg AO, Lohr KN. Screening for colorectal cancer in adults at average risk: A summary of the evidence for the U.S. Preventive Services Task Force. Ann Intern Med. 2002;137:132-141.

9. Smith RA, von Eschenbach AC, Wender R, et al. American Cancer Society guidelines for the early detection of cancer: Update of early detection guidelines for prostate, colorectal, and endometrial cancers. Also: Update 2001-Testing for early lung cancer detection. CA Cancer J Clin. 2001;51: $38-75$.

10. Griffin PM, Liff JM, Greenberg RS, Clark WS. Adenocarcinomas of the colon and rectum in persons under 40 years old. A population-based study. Gastroenterology. 1991;100: 1033-1040.

11. Lee PY, Fletcher WS, Sullivan ES, Vetto JT. Colorectal cancer in young patients: Characteristics and outcome. Am Surg. 1994;60:607-612.

12. Mitry E, Benhamiche AM, Jouve JL, Clinard F, Finn-Faivre C, Faivre J. Colorectal adenocarcinoma in patients under 45 years of age: Comparison with older patients in a welldefined French population. Dis Colon Rectum. 2001;44: 380-387.

13. Morris AM, Billingsley KG, Baxter NN, Baldwin LM. Racial disparities in rectal cancer treatment: A population-based analysis. Arch Surg. 2004;139:151-155.

14. Nelson RL, Dollear T, Freels S, Persky V. The relation of age, race, and gender to the subsite location of colorectal carcinoma. Cancer. 1997;80:193-197.

15. Troisi RJ, Freedman AN, Devesa SS. Incidence of colorectal carcinoma in the U.S.: An update of trends by gender, race, age, subsite, and stage, 1975-1994. Cancer. 1999;85:16701676.

16. Jackson-Thompson J, German RR, Ahmed F, Lai S, Friedman C. Descriptive epidemiology of colorectal cancer in the United States, 1998-2001. Cancer. 2006;107(5 Suppl):1103-1111.

17. Fritz A, Percy C, Jack A, et al. International Classification of Diseases for Oncology. 3rd ed. Geneva, Switzerland: World Health Organization; 2000.

18. Young JL, Roffers SD, Ries LAG, Fritz AG, Hurlbut AA. SEER Summary Staging Manual-2000: Codes and Coding Instructions. Bethesda, MD: National Cancer Institute; 2001.

19. Surveillance Research Program, National Cancer Institute. SEER*Stat software, version 6.1.4. Available at: www.seer. cancer.gov/seerstat. Accessed February 6, 2006.

20. Fay MP, Feuer EJ. Confidence intervals for directly standardized rates: A method based on the gamma distribution. Stat Med. 1997;16:791-801.

21. Marrett LD, Frood J, Nishri D, Ugnat AM. Cancer incidence in young adults in Canada: Preliminary results of a cancer surveillance project. Chronic Dis Can. 2002;23:58-64. 
22. Semmens JB, Platell C, Threlfall TJ, Holman CD. A population-based study of the incidence, mortality and outcomes in patients following surgery for colorectal cancer in Western Australia. Aust N Z J Surg. 2000;70:11-18.

23. Bulow S. Colorectal cancer in patients less than 40 years of age in Denmark, 1943-1967. Dis Colon Rectum. 1980;23:327336.

24. Chien C, Morimoto LM, Tom J, Li CI. Differences in colorectal carcinoma stage and survival by race and ethnicity. Cancer. 2005;104:629-639.

25. Wu X, Chen VW, Martin J, et al. Subsite-specific colorectal cancer incidence rates and stage distributions among Asians and Pacific Islanders in the United States, 1995 to 1999. Cancer Epidemiol Biomarkers Prev. 2004;13:1215-1222.

26. Wu XC, Chen VW, Steele B, et al. Cancer incidence in adolescents and young adults in the United States, 1992-1997. J Adolesc Health. 2003;32:405-415.

27. Palmer ML, Herrera L, Petrelli NJ. Colorectal adenocarcinoma in patients less than 40 years of age. Dis Colon Rectum. 1991;34:343-346.

28. Lynch HT, Lemon SJ, Karr B, et al. Etiology, natural history, management and molecular genetics of hereditary nonpolyposis colorectal cancer (Lynch syndromes): Genetic counseling implications. Cancer Epidemiol Biomarkers Prev. 1997; 6:987-991.

29. Vasen HF, Watson P, Mecklin JP, Lynch HT. New clinical criteria for hereditary nonpolyposis colorectal cancer (HNPCC, Lynch syndrome) proposed by the International Collaborative group on HNPCC. Gastroenterology. 1999;116:14531456.

30. Marchbanks PA, McDonald JA, Wilson HG, et al. Oral contraceptives and the risk of breast cancer. $N$ Engl J Med. 2002;346:2025-2032.
31. National Cancer Institute. Cancer family registries website. Available at: http://www.cfr.epi.uci.edu/nci/newoverview. htm. Accessed February 6, 2006.

32. Ezzo JA, Sullivan JF, Mack RE. Carcinoma of the colon under the age of 40. Ann Intern Med. 1958;49:321-325.

33. Parramore JB, Wei JP, Yeh KA. Colorectal cancer in patients under forty: Presentation and outcome. Am Surg. 1998;64:563-567.

34. Adkins RB Jr, DeLozier JB, McKnight WG, Waterhouse G. Carcinoma of the colon in patients 35 years of age and younger. Am Surg. 1987;53:141-145.

35. Pitluk H, Poticha SM. Carcinoma of the colon and rectum in patients less than 40 years of age. Surg Gynecol Obstet. 1983;157:335-337.

36. American Cancer Society. Cancer Facts and Figures 2005. Atlanta, GA: American Cancer Society; 2005.

37. Slattery ML, Edwards S, Curtin K, et al. Physical activity and colorectal cancer. Am J Epidemiol. 2003;158:214-224.

38. World Health Organization,International Agency for Research on Cancer.IARC Handbooks of Cancer Prevention, Vol 6: Weight Control and Physical Activity. Lyon, France: IARC Press; 2002.

39. Agrawal S, Bhupinderjit A, Bhutani MS, et al. Colorectal cancer in African Americans. Am J Gastroenterol. 2005;100: 515-523.

40. Slattery ML, Edwards SL, Ma KN, Friedman GD. Colon cancer screening, lifestyle, and risk of colon cancer. Cancer Causes Control. 2000;11:555-563.

41. U.S. Preventive Services Task Force. Screening for colorectal cancer: Recommendation and rationale. Ann Intern Med. 2002;137:129-131.

42. Wu X, Cokkinides V, Chen VW, Ren Y, Martin HJ, Ellison GL. Association of subsite-specific colorectal cancer incidence rate and stage at diagnosis with county-poverty level. Cancer. 2006;107(5 Suppl):1121-1127. 